\title{
Gender Differences in In-Hospital Outcome in Non ST- Elevation Myocardial Infarction
}

\author{
Mohammad Anisul Goni Khan¹, Nur Hossain², Zakir Hossain ${ }^{3}$, Md. Sajjadur Rahman ${ }^{4}$, Md. Shuaib Ahmed ${ }^{5}$
}

\begin{abstract}
:
Among the different types of acute coronary syndrome (ACS), non ST-elevation MI (NSTEMI) is about $25 \%$. Women with ST-segment-elevation myocardial infarction have a worse prognosis than men. However, information about the prognosis of women with non-STEMI is scarce. There are several studies regarding gender difference in NSTEMI. Almost all of these studies were done in western \& European countries. Though in third world countries like Bangladesh the patients of NSTEMI are
\end{abstract}

found in large number, limited data are available in this situation. The aim of the study is to determine difference in effect between the genders, in real life patients, with non-invasive treatment. So that definite measures can be formulated to the patients properly of that gender specific group.

Key word: Non-ST segment elevation myocardial infarction, Gender, ACS

\section{Introduction:}

The myocardial infarction (MI) mortality has decreased markedly during recent decades, a decrease that has multiple causes. In spite of improvements, the incidence of acute MI has remained high and cardiovascular disease is still the leading cause of death, afflicting almost $50 \%$ of both men and women. Coronary heart disease accounts for most of the cardiovascular events, and $\mathrm{MI}$ is the single most important contributor to the mortality and morbidity ${ }^{1}$.

Historically, fewer women than men have been included in studies on coronary heart disease (CHD). Whether this is caused by lower incidence in women, especially at younger age, or actual exclusion of women from the

1. Medical Officer, National Institute of Cardiovascular Diseases \& Hospital, Dhaka.

2. Professor and Head,Department of Cardiology, SSMC \& Mitford Hospital, Dhaka.

3. Assistant Professor, Department of Cardiology, SSMC \& Mitford Hospital, Dhaka.

4. Assistant Registrar, National Institute of Cardiovascular Diseases \& Hospital, Dhaka.

5. Assistant Surgeon, Golapganj UHC, Sylhet.

Address of Correspondence: Dr. Mohammad Anisul Goni Khan, Medical Officer, National Institute of Cardiovascular Diseases, Dhaka, Bangladesh. E-mail: drknightssmc@gmail.com trials have been debated ${ }^{2}$. The consequence is that evidence base for several treatments are fewer firms for women than for men. Lack of gender-specific knowledge has emerged as an important issue in the management of non ST-elevation acute coronary syndromes where some data have indicated a difference in benefit from a routine invasive strategy according to gender ${ }^{3-6}$.

There are also reports that women have been managed less intensively, with worse outcome, compared to men. For example, women have less often received reperfusion therapy, early antithrombotic therapy and antiplatelet therapy at discharge ${ }^{7,8}$. Moreover, men have more often been referred for coronary angiography. There are several important differences in background characteristics between a female and a male population with acute coronary syndromes (ACS); for example, females are older and have more co-morbid conditions ${ }^{9}$.

Today, ACS is the leading cause of death in both gender of the western world and during the last two decades there has been an ongoing debate about women and ACS and whether women and men suffering from this syndrome differ in baseline characteristics, clinical presentation, treatment and outcome ${ }^{10}$. 
Early mortality among patients hospitalized with an acute MI has been consistently reported to be higher among women than men. An important question has been whether women tend to be treated less vigorously than men although current knowledge from a couple of studies strongly indicates that women in most aspects benefit as much as men from recommended therapies. In contrast to these studies, FRISC II and RITA 3 trials reported worsening outcomes among women with ACS who were treated invasively. This finding has raised doubt as to whether treatment in women and men should be similar ${ }^{11}$.

Other studies investigating age-sex differences in shortterm mortality beyond the hospital stay support higher long-term mortality rates among women, particularly younger women, compared with men at same ages. In a study from 2001. Vaccarino et al observed that women younger than 60 years of age had a higher mortality rate than men and the mortality risk for women compared with men decreased with increasing age, to the point where women in the oldest age groups showed a lower 2 year mortality rate than men of similar age $\mathrm{e}^{12,13}$.

Studies comparing management and outcome in men and women are, for obvious reasons, not randomized why fair comparisons rely on statistical methods to adjust for observed differences in background characteristics $^{14,15}$. To decide whether it is gender per se or other characteristics that account for observed differences in management and outcome between the genders, large study populations, with information on potential confounders, are needed to perform proper adjustments ${ }^{16-17}$.
To improve the individual management of NSTEMI patients it is important to clarify if we, in real life clinical practice, treat women differently than men. It is also important to evaluate if there are differences in effect of treatments between the genders, and if observed differences are due to gender per se.

\section{Methodology:}

A hospital-based cross-sectional study. It was done on one year duration (July 2014 - June 2015) in the coronary care unit ( CCU ) of Sir Salimullah Medical College \& Mitford Hospital, Dhaka. Study population were patients attending at hospital having Non ST-elevation MI screened out by clinical examination and electrocardiography (ECG) and biochemical marker (S.Troponin I). Considering the inclusion and exclusion criteria a total number of 115 patients presented with NSTEMI were included in the study.

After collection all the data were checked and edited. Then data were entered into computer with the help of software SPSS for Windows programmed version 16 . After frequency run, data were cleaned and frequencies were checked. An analysis plan were developed keeping in view with the objectives of the study.

\section{Results:}

The 115 Non ST Elevated patients were included in the study comprising 50 women and 65 men. The study population consisted of 51 patients ( 16 women, 35 men) aged under 50 years and 64 patients (34 women, 30 men) aged 50 years or older. The mean age of NSTEMI in study population is 52.45 years and the mean age of women in the study is 55.70 years and the mean age of men in the study is 49.49 years.

Table-I

Distribution of risk factors according to sex

\begin{tabular}{lcccccc}
\hline Risk factors & \multicolumn{2}{c}{$<50$ years } & $p$ value & \multicolumn{2}{c}{$\geq 50$ years } & \multicolumn{2}{c}{$p$ value } \\
\cline { 2 - 4 } & MaleN=35 & FemaleN=16 & & & MaleN=30 & FemaleN=34 \\
\hline HTN & $12(34.3)$ & $11(68.7)$ & 0.02 & $15(50)$ & $27(79.4)$ & 0.01 \\
DM & $06(17.1)$ & $09(56.2)$ & 0.007 & $14(46.7)$ & $11(32.4)$ & 0.24 \\
CKD & - & - & - & $02(6.7)$ & $02(5.9)$ & 1.0 \\
Dyslipidemia & $12(34.3)$ & $03(18.7)$ & 0.33 & $05(16.7)$ & $03(8.8)$ & 0.45 \\
Smoking & $27(77.1)$ & $01(6.3)$ & $<0.001$ & $16(53.3)$ & $05(14.7)$ & 0.001 \\
Family history of & $07(20.0)$ & $06(37.5)$ & 0.18 & $04(13.3)$ & $08(23.5)$ & 0.29 \\
coronary heart & & & & & & \\
disease & & & & & & \\
\hline
\end{tabular}

HTN - Hypertension, DM - Diabetes Mellitus, CKD - Chronic kidney disease 
Table-II

In hospital outcome according to distribution of gender

\begin{tabular}{lcccc}
\hline Outcome & Sex & Sotal & p value \\
& 16 & Female $(\mathrm{n}=50)$ & & \\
\hline Persistent chest pain & 2 & 23 & 39 & 0.030 \\
Heart failure & 2 & 3 & 5 & 0.035 \\
Cardiogenic shock & 1 & 3 & 5 & 0.34 \\
Arrhythmia & 1 & 2 & 0.043 \\
Reinfarction & 2 & 1 & 3 & 0.49 \\
Major bleeding & 2 & 1 & 3 & 0.49 \\
CVD/Stroke/TIA & 2 & 1 & 3 & 0.49 \\
Death & 2 & 1 & 3 & 0.49 \\
\hline
\end{tabular}

CVD - cerebro-vascular disease, TIA - transient ischemic attack

Most patients have no changes in ECG. Commonly ST depression and $\mathrm{T}$ wave inversion are significantly seen in women. Other ECG changes include atrial fibrillation, LBBB or RBBB pattern but all of these changes have no significance differences in relation to sex.

Younger women $<50$ years were significantly more frequently diagnosed with arterial hypertension and diabetes than men, and they were significantly less frequently current smokers. Older women $>50$ years more often were hypertensive, while men more often had a history of smoking. Apart from smoking, the frequency of cardiovascular risk factors was similar in both female age groups, while the incidence of arterial hypertension, diabetes was higher in older than in younger men.

Regarding in hospital outcome there is persistent chest pain in $23(46 \%)$ women and $16(24.6 \%)$ men heart failure is present in $3(6 \%)$ women and $2(3.1 \%)$. The differences in incidence of persistent chest pain and heart failure are statistically significant between the two genders.

\section{Discussion:}

The debate on the reasons for the differences in mortality and morbidity between women and men with NSTEMI is still ongoing and no full agreement has been reached so far. Many researchers associate poorer outcomes in women with co-morbidities, clinical manifestation and adverse events.

\section{Risk factors and baseline characteristics}

In the present study, there were more men in the age group of $<50$ years, while in the older group the percentage of men and women were practically the same. Women tend to live longer and develop cardiovascular disease at a later age, which means that both in younger and older age groups women are older than men and they have additional risk factors. In the general population of patients with NSTEMI, there is a discrepancy in the prevalence of conventional risk factors (arterial hypertension, diabetes, dyslipidemia, smoking , obesity, prior MI) between sex .

Women $<50$ years tend to have hypertension, diabetes and family history of coronary heart diseases more often, while smoking and dyslipidemia are more frequent in men. The incidence of hypertension increases with age in both sexes. It seems that the frequency of diabetes mellitus is more in women than men of age $<50$ years but it is reverse in age $>50$ years patients. There is no significant differences in women and men regarding chronic kidney disease (CKD), dyslipidemia and family history of coronary heart disease.

\section{Electrocardiographic changes:}

A negative prognostic value of ST-segment depression and T-wave inversion in the index ECG is well established. In our study, there was significant difference in STsegment depression and $\mathrm{T}$-wave inversion between men and women <50 years age groups; however, atrial fibrillation was observed more frequently in older men $>50$ years.

\section{Echocardiographic changes:}

In this study we have found that women $<50$ years have significant echocardiographic changes. There were only significant wall motion abnormalities in case of inferior and lateral wall which was more in female patients. The mean ejection fraction was found more in men $(E F=57.97 \%)$ than women $(E F=55.48 \%)$. But it was not significant.

Regarding diastolic dysfunction there was no significant difference in women and men. 


\section{In-hospital management}

In our study we have found that women were more likely to be treated with beta-blockers, angiotensin converting enzyme inhibitor (ACEi) and diuretics which may reflect the higher rate of hypertension and heart failure. After age adjustment there was no difference between the gender in treatment with heparin/low molecular weight heparin (LMWH), statins, nitrates were used infrequently in both men and women in our data, but less often in women.

\section{Complications:}

In our observation $24.6 \%$ men experienced persistent chest pain in comparison to $46 \%$ women and it was statistically significant. The incidence of heart failure increases with age and reaches $12.5 \%$ in patients younger than 65 years and $22 \%$ to $41 \%$ in patients over 65 years. In many registries, and also in our study, no differences between young men and women were observed, while women had developed heart failure $(6.0 \%)$ more than men $(3.1 \%)$ and it is statistically significant. Another important finding was arrhythmia, statistically significant in men $(20 \%)$ than women $(8.0 \%)$. Other complications like cardiogenic shock, re-infarction, cerebro-vascular events were not found to differ significantly between the groups.

\section{Mortality}

In our study we have found that in hospital death occurred only in 2 men (3.1\%) and 1 women (2\%) and the difference was not significant.

\section{Conclusion:}

In the present study men represent a large population of patients with NSTEMI than women. Smoking is the most alarming risk factors in young male while diabetes and hypertension in young female. There are substantial differences in baseline characteristics between a male and a female population with NSTEMI. Women are older and more likely to have a history of diabetes, hypertension and heart failure. Men are more likely to have a history of NSTEMI. Women are less likely to be admitted to coronary care units. Women receive more diuretics, beta-blockers and angiotensin converting enzyme inhibitor (ACEi) or angiotensin receptor blocker (ARB) in relation to men. Women show worse prognosis regarding heart failure and persistent chest pain.

Risk factors identification, early diagnosis and management are very crucial in the primary and secondary prevention in young patient with CAD. Adoption and application of new knowledge regarding sex differences will hopefully lead to improve outcomes.

\section{Reference:}

1. Maynard C, Every NR, Martin JS, Kudenchuk PJ, Weaver WD. Association of gender and survival in patients with acute myocardial infarction. Arch Intern Med 1997;157(12):1379-84.

2. Barrett-Connor E. Sex differences in coronary heart disease. Why are women so superior? The 1995 Ancel Keys Lecture. Circulation 1997;95(1):252-64.

3. Wingard DL, Cohn BA, Kaplan GA, Cirillo PM, Cohen RD. Sex differentials in morbidity and mortality risks examined by age and cause in the same cohort. Am J Epidemiol 1989;130(3):601-10.

4. Ahmed S, Cannon CP, Giugliano RP, et al. The independent and combined risk of diabetes and non endstage renal impairment in non ST segment elevation acute coronary syndromes. Int J Cardiol. 2008; 131: 105-112.

5. Gilat D, Goldbourt U, Reicher-Reiss H, Zion M, Kaplinsky E, Behar S. [Prognosis of acute myocardial infarction in the elderly. SPRINT Study Group]. Harefuah 1993;124(10):601-3, 668.

6. Avezum A, Makdisse M, Spencer F, Gore JM, Fox $\mathrm{KA}$, Montalescot $\mathrm{G}$, et al. Impact of age on management and outcome of acute coronary syndrome: observations from the Global Registry of Acute Coronary Events (GRACE). Am Heart J 2005;149(1):67-73.

7. Mehta RH, Rathore SS, Radford MJ, Wang Y, Wang $\mathrm{Y}$, Krumholz HM. Acute myocardial infarction in the elderly: differences by age. J Am Coll Cardiol 2001;38(3):736-41.

8. Goldberg RJ, McCormick D, Gurwitz JH, Yarzebski J, Lessard D, Gore JM. Age-related trends in shortand long-term survival after acute myocardial infarction: a 20-year population-based perspective (1975-1995). Am J Cardiol 1998;82(11): 1311-7.

9. Yan RT, Yan AT, Tan M, Chow CM, Fitchett DH, Ervin $\mathrm{FL}$, et al. Age-related differences in the management and out-come of patients with acute coronary syndromes. Am Heart J 2006;151:352-9.

10. Thiemann DR, Coresh J, Schulman SP, Gerstenblith G, Oetgen WJ, Powe NR. Lack of benefit for intravenous thrombolysis in patients with myocardial infarction who are older than 75 years. Circulation 2000;101(19):2239-46. 
11. Stenestrand $U$, Wallentin L. Fibrinolytic therapy in patients 75 years and older with ST-segmentelevation myocardial infarc-tion: one-year follow-up of a large prospective cohort. Arch Intern Med 2003;163(8):965-71.

12. Vaccarino V, Krumholz HM, Yarzebski J, Gore JM, Goldberg RJ. Sex differences in 2-year mortality after hospital discharge for myocardial infarction. Intern Med 2001;134(3):173-81.

13. Alexander KP, Newby LK, Cannon CP, et al; American Heart Association Council on Clinical Cardiology; Society of Geriatric Cardiology. Acute coronary care in the elderly, part I: Non ST segment elevation acute coronary syndromes: a scientific statement for healthcare professionals from the American Heart Association Council on Clinical Cardiology: in collaboration with the Society of Geriatric Cardiology. Circulation. 2007; 115:2549-2569.
14. Anand SS, Islam S, Rosengren A, Franzosi MG, Steyn K, Yusufali AH, et al. Risk factors for myocardial infarction in women and men: insights from the INTERHEART study. Eur Heart J. 2008 Apr;29(7):932-40.

15. Braunwald E: Unstable angina: An etiologic approach to management. Circulation 98: 2219, 1998.

16. Mueller C, Neumann FJ, Perach W, et al. Prognostic value of the admission electrocardiogram in patients with unstable angina/non ST segment elevation myocardial infarction treated with very early revascularization. Am J Med. 2004; 117: 145-150.

17. Stone PH, Thompson B, Anderson HV, Kronenberg MW, Gibson RS, Rogers WJ, et al. Influence of race, sex, and age on management of unstable angina and non-Q-wave myocardial infarction: The TIMI III registry. JAMA 1996;275(14):1104-12. 